\title{
The real COVID-19 pandemic dynamics in Qatar in 2021: simulations, predictions and verifications of the SIR model
}

\section{A real dinâmica da pandemia COVID-19 no Catar em 2021: simulações, previsões e verificações do modelo SIR}

\author{
Igor Nesteruk ${ }^{1}$
}

\begin{abstract}
The third COVID-19 pandemic wave in Qatar was simulated with the use of the generalized SIR-model and the accumulated number of cases reported by Johns Hopkins University for the period: April 25 - May 8, 2021. The results were compared with the SIR simulations performed before for the second wave and the number of laboratory-confirmed cases in the first half of 2021. Despite the mass vaccination that began in December 2020, Qatar experienced a new epidemic wave in March-April 2021. As of the end of June 2021, the positive effects of vaccination were still unclear, although the number of fully vaccinated was already approaching half the population. Additional simulations have demonstrated that many COVID-19 cases are not detected. The real accumulated number of cases in Qatar can exceed the laboratory-confirmed one more than 5 times. This fact drastically increases the probability of meeting an infectious person and the epidemic duration.
\end{abstract}

Keywords: COVID-19 pandemic. vaccination efficiency. Epidemic dynamics in Qatar. SIR model. Parameter identification.

\section{Resumo}

A terceira onda pandêmica de COVID-19 no Catar foi simulada com o uso do modelo SIR generalizado e os dados acumulados de casos relatados pela Universidade Johns Hopkins para o período: 25 de abril a 8 de maio de 2021. Os resultados foram comparados com as simulações SIR realizadas anteriormente para a segunda onda e o número de casos confirmados em laboratório no primeiro semestre de 2021. Apesar da vacinação em massa que começou em dezembro de 2020, o Catar experimentou uma nova onda epidêmica em março-abril de 2021. No final de junho de 2021, os efeitos positivos da vacinação ainda não eram claros, embora o número de vacinados completos já se aproximasse da metade da população. Simulações adicionais demonstraram que muitos casos COVID-19 não são detectados. O número real de casos acumulados no Catar pode ultrapassar aquele confirmado em laboratório em mais de 5 vezes. Esse fato aumenta drasticamente a probabilidade de encontro com uma pessoa infectada e a duração da epidemia.

Palavras-chave: Pandemia do COVID-19. Eficácia da vacinação. Dinâmica da epidemia no Qatar. Modelo SIR. Identificação de parâmetros.

${ }^{1} \mathrm{PhD}$., Institute of Hydromechanics, National Academy of Sciences of Ukraine, Kyiv, Ukraine, E-mail: inesteruk@ yahoo.com 


\section{Introduction}

The COVID-19 pandemic dynamics in Qatar was simulated with the use of SEIR-model, susceptible-exposed-infected-removed (FAHMAYA; ELDESOUKYA; MOHAMED, 2020), and SEIRD-model, susceptible-exposed-infected-removed-dead (GHANAM; BOONE; ABDEL-SALAM, 2020). Some recent simulations of the SIR model, susceptible-infected-removed (NESTERUK; BENLAGHA, 2021), were based on the dataset about the number of cases in December 2020. The vaccination was started in this country on December 23, 2020.

In this study we will use the information about the accumulated number of cases from COVID-19 Data Repository by the Center for Systems Science and Engineering (CSSE) at Johns Hopkins University (JHU) in OUR WORLD IN DATA (2021). We will analyze the recent epidemic dynamics in Qatar, make some predictions taking into account the incompleteness of the statistical information with the use of method proposed in Nesteruk (2021a) and discuss the efficiency of vaccination.

\section{Materials and methods}

\section{Data}

We will use two data sets regarding the accumulated numbers of confirmed COVID-19 cases $V_{j}$, number of vaccinated people $P_{j}$ and number of vaccinations $Q_{j}$ in Qatar from JHU (OUR WORLD IN DATA, 2021). These values and corresponding moments of time $t_{j}$, measured in days, are shown in Table 1.

For the SIR model simulations we have used the values of $V_{j}$ and $t_{j}$ corresponding to the time period $T_{c 3}$ : April 25 May 8, 2021 during the third epidemic wave in Qatar. Other values presented in Table 1 and datasets available in Nesteruk and Benlagha (2021) were used only for comparisons and verifications of the calculations.

\section{Generalized SIR model and parameter identification pro- cedure}

The classical SIR model for an infectious disease (KERMACK; MCKENDRICK, 1927; LANGEMANN; NESTERUK; PRESTIN, 2016; MURRAY, 2002) was generalized in Nesteruk (2021a, 2021b) to simulate different epidemic waves.

We suppose that the SIR model parameters are constant for every epidemic wave, i.e. for the time periods: $t_{i}^{*} \leq t \leq t_{i+1}^{*}, \quad i=1,2,3, \ldots$.
Then for every wave we can use the equations, similar to Kermack and Mckendrick (1927), Langemann, Nesteruk and Prestin (2016) and Murray (2002), given by:

$$
\begin{gathered}
\frac{d S(t)}{d t}=-\alpha_{i} S(t) I(t), \\
\frac{d I(t)}{d t}=\alpha_{i} S(t) I(t)-\rho_{i} I(t), \\
\frac{d R(t)}{d t}=\alpha_{i} I(t),
\end{gathered}
$$

where $S(t)$ is the number of susceptible persons, who are sensitive to the pathogen and not protected; $I(t)$ is the number of infectious persons, who are sick and spread the infection; and $R(t)$ is the number of removed persons, who no longer spread the infection. Parameters $\alpha_{i}$ and $\rho_{i}$, in the equations (1)-(3), are supposed to be constant for every epidemic wave.

It must be noted that $I(t)$ is not the number of active cases. People can be ill, among active cases, but isolated. In means, that they dont spread the infection anymore. There are many people spreading the infection but not tested and registered as active cases. The use of number of active cases as $I(t)$ in some papers is the principal mistake which may lead to incorrect results.

To determine the initial conditions for the set of equations (1)-(3), let us suppose that at the $t_{i}^{*}$ beginning of every epidemic wave the following initial conditions are valid:

$$
\begin{gathered}
I\left(t_{i}^{*}\right)=I_{i}, \\
R\left(t_{i}^{*}\right)=R_{i}, \\
S\left(t_{i}^{*}\right)=N_{i}-I_{i}-R_{i}
\end{gathered}
$$

and

$$
N_{i}=S+I+R
$$

In Nesteruk (2021a, 2021b) the set of differential equations (1)-(3) was solved by introducing the function

$$
V(t)=I(t)+R(t)
$$

corresponding to the number of victims or the cumulative number of cases. The analytical formulas for this exact solution; the saturation levels $S_{i \infty} ; V_{i \infty}=N_{i}-S_{i \infty}$, corresponding the infinite time moment, and the final day of the $i$-th epidemic wave, calculated with the use of condition that the number of persons spreading the infection is less than 1, can be found in Nesteruk (2021a, 2021b). 
Table 1 - Cumulative numbers of confirmed Covid-19 cases in Qatar, in February-June 2021.

\begin{tabular}{|c|c|c|c|c|c|c|c|}
\hline Day & $\begin{array}{l}\text { Number of } \\
\text { cases } V_{j}\end{array}$ & $\begin{array}{l}\text { Number of } \\
\text { vaccinations } \\
Q_{j}\end{array}$ & $\begin{array}{l}\text { Number of } \\
\text { vaccinated } \\
\text { people } P_{j}\end{array}$ & Day & $\begin{array}{l}\text { Number of } \\
\text { cases } V_{j}\end{array}$ & $\begin{array}{l}\text { Number of } \\
\text { vaccinations } \\
Q_{j}\end{array}$ & $\begin{array}{l}\text { Number of } \\
\text { vaccinated } \\
\text { people } P_{j}\end{array}$ \\
\hline \multicolumn{2}{|c|}{ February } & & & \multicolumn{2}{|c|}{ April (cont.) } & & \\
\hline 21 & 160426 & - & - & 23 & 200778 & 1372396 & - \\
\hline 22 & 160889 & - & - & 24 & 201496 & 1394781 & - \\
\hline 23 & 161344 & - & - & 25 & 202201 & 1415761 & - \\
\hline 24 & 161803 & - & - & 26 & 202904 & 1442708 & - \\
\hline 25 & 162268 & - & - & 27 & 203599 & 1469633 & - \\
\hline 26 & 162737 & - & - & 28 & 204289 & 1496833 & - \\
\hline 27 & 163197 & - & - & 29 & 204976 & 1526775 & 971973 \\
\hline 28 & 163664 & - & - & 30 & 205652 & 1556203 & 989627 \\
\hline \multicolumn{2}{|c|}{ March } & & & \multicolumn{2}{|l|}{ May } & & \\
\hline 1 & 164137 & - & - & 1 & 206302 & 1579002 & 1002748 \\
\hline 2 & 164600 & - & - & 2 & 206948 & 1603913 & 1017019 \\
\hline 3 & 165071 & - & - & 3 & 207592 & 1635398 & 1031300 \\
\hline 4 & 165546 & - & - & 4 & 208232 & 1670911 & 1047196 \\
\hline 5 & 166015 & - & - & 5 & 208877 & 1701914 & 1064294 \\
\hline 6 & 166475 & - & - & 6 & 209470 & 1732471 & 1080415 \\
\hline 7 & 166949 & - & - & 7 & 210070 & 1762545 & 1094976 \\
\hline 8 & 167417 & - & - & 8 & 210603 & 1787160 & 1103747 \\
\hline 9 & 167888 & - & - & 9 & 210992 & 1813240 & 1115842 \\
\hline 10 & 168361 & - & - & 10 & 211389 & 1844658 & 1127091 \\
\hline 11 & 168829 & - & - & 11 & 211732 & 1876178 & 1137843 \\
\hline 12 & 169284 & - & - & 12 & 212124 & 1911663 & 1149854 \\
\hline 13 & 169767 & - & - & 13 & 212423 & 1944628 & 1160213 \\
\hline 14 & 170252 & - & - & 14 & 212667 & 1976748 & 1168975 \\
\hline 15 & 170733 & - & - & 15 & 212927 & 2002018 & 1177725 \\
\hline 16 & 171212 & - & - & 16 & 213183 & 2035475 & 1190700 \\
\hline 17 & 171701 & - & - & 17 & 213485 & 2073354 & 1206737 \\
\hline 18 & 172200 & - & - & 18 & 213855 & 2109980 & 1221996 \\
\hline 19 & 172697 & - & - & 19 & 214150 & 2150749 & 1240202 \\
\hline 20 & 173206 & - & - & 20 & 214463 & 2190807 & 1261828 \\
\hline 21 & 173709 & - & - & 21 & 214830 & 2233616 & 1288584 \\
\hline 22 & 174228 & - & - & 22 & 215160 & - & - \\
\hline 23 & 174762 & - & - & 23 & 215443 & 2293240 & 1321233 \\
\hline 24 & 175332 & 658325 & - & 24 & 215742 & 2329338 & 1341921 \\
\hline 25 & 175919 & 679278 & - & 25 & 216091 & 2365647 & 1361511 \\
\hline 26 & 176521 & 701943 & - & 26 & 216397 & 2403165 & 1381456 \\
\hline 27 & 177135 & 721236 & - & 27 & 216683 & 2440930 & 1400720 \\
\hline 28 & 177774 & 740309 & - & 28 & 216885 & 2475837 & 1420090 \\
\hline 29 & 178464 & 765110 & - & 29 & 217041 & 2491638 & 1430121 \\
\hline 30 & 179184 & 790676 & - & 30 & 217230 & 2514585 & 1443882 \\
\hline 31 & 179964 & 816484 & - & 31 & 217458 & 2545193 & 1461871 \\
\hline \multicolumn{2}{|l|}{ April } & \multirow[b]{2}{*}{842000} & \multirow[b]{2}{*}{ - } & \multicolumn{2}{|l|}{ June } & & \\
\hline 1 & 180804 & & & 1 & 217688 & 2574692 & 1479717 \\
\hline 2 & 181678 & 867209 & - & 2 & 217882 & 2600344 & 1494265 \\
\hline 3 & 182548 & 889202 & - & 3 & 218080 & 2622285 & 1510561 \\
\hline 4 & 183424 & 910851 & - & 4 & 218263 & 2643573 & 1526103 \\
\hline 5 & 184334 & 934843 & - & 5 & 218455 & 2656695 & 1531477 \\
\hline 6 & 185261 & 961555 & - & 6 & 218627 & 2676239 & 1541863 \\
\hline 7 & 186201 & 987673 & - & 7 & 218798 & 2700942 & 1554740 \\
\hline 8 & 187150 & 1012716 & - & 8 & 218980 & 2716670 & 1561481 \\
\hline 9 & 188100 & 1041632 & - & 9 & 219138 & 2729437 & 1566366 \\
\hline 10 & 189064 & 1062250 & - & 10 & 219281 & 2748452 & 1572212 \\
\hline 11 & 190025 & 1079776 & - & 11 & 219466 & 2768028 & 1578669 \\
\hline 12 & 190998 & 1104726 & - & 12 & 219613 & 2780916 & 1583143 \\
\hline 13 & 191979 & 1131631 & - & 13 & 219730 & 2795091 & 1587414 \\
\hline 14 & 192963 & 1159479 & - & 14 & 219887 & 2813022 & 1593600 \\
\hline 15 & 193952 & 1183191 & - & 15 & 220033 & 2833984 & 1601801 \\
\hline 16 & 194930 & 1209648 & - & 16 & 220198 & 2845587 & 1605854 \\
\hline 17 & 195757 & 1225110 & - & 17 & 220325 & 2856149 & 1609775 \\
\hline 18 & 196580 & 1248229 & - & 18 & 220509 & 2868162 & 1614039 \\
\hline 19 & 197476 & 1271478 & - & 19 & 220693 & 2876509 & 1616899 \\
\hline 20 & 198361 & 1296520 & - & 20 & 220800 & 2886323 & 1620571 \\
\hline 21 & 199180 & 1320866 & - & 21 & 220930 & 2898814 & 1625178 \\
\hline \multirow[t]{2}{*}{22} & 199980 & 1345423 & - & 22 & 221119 & 2908963 & 1629077 \\
\hline & & & & 23 & 221273 & 2926066 & 1635054 \\
\hline
\end{tabular}

Source: Our World in Data (2021). 
For many epidemics, including the COVID-19 pandemic, we cannot observe dependencies $S(t), I(t)$ and $R(t)$, but observations of the accumulated number of cases $V_{j}$ corresponding to moments of time $t_{j}$ provide information for direct assessments of the dependence $V(t)$. In the case of a new epidemic, the values of its parameters are unknown and must be identified with the use of limited data sets. For the second and next epidemic waves, $i>1$, the moments of time $t_{i}^{*}$ corresponding to their beginning are known. Therefore, the exact solution depend only on five parameters $N_{i}, I_{i}, R_{i}, \alpha_{i}, v_{i}=\rho_{i} / \alpha_{i}$ (NESTERUK, 2021a, 2021b), when the all the cases are registered and the number of victims $V_{j}$ is only a random realization of the theoretical dependence, equation (4).

The real number of COVID-19 cases is much higher than the number of laboratory-confirmed patients (WEINBERGER et al., 2020; NESTERUK, 2021a, 2021b; NOVAK, 2021; ZHEN, 2020), since many patients have no symptoms or make no tests.

If we assume, that data set $V_{j}$ is incomplete and there is a constant coefficient $\beta_{i} \geq 1$, relating the registered and real number of cases during the $i$-th epidemic wave:

$$
V\left(t_{j}\right)=\beta_{i} V_{j}
$$

then the number of unknown parameters increases by one.

The values $V_{j}$, corresponding to the moments of time $t_{j}$, the exact solution (NESTERUK, 2021a, 2021b) and equation (5) can be used to find the optimal values of the parameters $N_{i}, I_{i}, R_{i}, v_{i}, \alpha_{i}, \beta_{i}$ providing the maximum value of the correlation coefficient $r_{i}$, see details in Nesteruk (2021a, 2021c).

\section{Results}

First, we have calculated the optimal vales of parameters for the third wave, of the COVID-19 pandemic in Qatar assuming that the dataset $V_{j}$ and $t_{j}$ reflects the real number of cases, i.e., we supposed that $\beta_{3}=1$. The results are shown in Table 2, third column.

The last column of the Table 2 represents the characteristics of the second wave, calculated in Nesteruk and Benlagha (2021) for $\beta_{2}=1$. It can be seen that the optimal values of parameters $N_{i}, v_{i}, \alpha_{i}$ and the final sizes $V_{i \infty}$ are rather different for the second and third pandemic waves in Qatar, see last two columns in Table 2, but the estimations of average time of spreading the infection $1 / \rho_{i} \approx 3.9$ days days and the epidemic duration are very close.
The corresponding SIR curves are shown in Figure 1 by black, wave for the period $T_{c 2}$ and red, wave for the period $T_{c 3}$, colors. "Solid lines" represent the number of victims $V(t)=R(t)+I(t)$, "dashed lines" the number of infectious persons $I(t)$ and "dotted lines" - the derivatives

$$
\frac{d V(t)}{d t}=\alpha_{i} S(t) I(t)
$$

Equation (6) follows from equations (2)-(4) and yields a theoretical estimation of the average daily number of new cases which can be calculated by numerical differentiation of the smoothed accumulated number of cases

$$
\bar{V}_{i}=\frac{1}{7} \sum_{j=i-3}^{j=i+3} V_{j}
$$

as follows:

$$
\left.\frac{d \bar{V}}{d t}\right|_{t=t_{i}} \approx \frac{1}{2}\left(\bar{V}_{i+1}-\bar{V}_{i-1}\right) .
$$

Values of the derivative (8) are shown in Figure 1, by blue "crosses", and illustrate that the experimental and theoretical estimation for the second epidemic wave, equation (6), black "dotted line", started to deviate after January 16, 2021. At the end of March 2021 there was a sharp increase of the averaged daily number of new cases.

In April 2021, the derivative, equation (8), was close to the theoretical estimation equation (6) for the third wave, compare blue "crosses" and the red "dotted line" in Figure 1 .

Blue "stars", in Figure 1, show the laboratoryconfirmed cases $V_{j}$ from Table 1 and corresponding Table in Nesteruk and Benlagha (2021). These values were used only to check the results of calculation, in comparison with red "circles" corresponding to $V_{j}$ values taken for SIR simulations of the third epidemic wave in Qatar.

It can be seen that the registered number of cases deviates from the theoretical curve for the second wave, compare the black "line" and blue "stars" in Figure 1.

The $V(t)=I(t)+R(t)$ curve for the third wave, calculated with the use of fresher dataset, is in good agreement with the accumulated number of cases confirmed after mid-March 2021, compare the red "line" and blue "stars" in Figure 1.

Assuming that the dataset $V_{j}$ does not reflect the real number of cases, we have calculated the optimal value of the visibility coefficient $\beta_{3}=5.308$, in equation (5), and other optimal vales of parameters for the third wave of the COVID-19 pandemic in Qatar. 
Table 2 - Calculated optimal values of SIR parameters and other characteristics of the second and third pandemic waves in Qatar.

\begin{tabular}{|c|c|c|c|}
\hline \multirow[b]{2}{*}{ Characteristics } & \multirow{2}{*}{$\begin{array}{c}\text { Invisible wave } \\
i=3, \beta_{3}=5.308\end{array}$} & \multicolumn{2}{|c|}{ Visible wave } \\
\hline & & $i=3, \beta_{3}=1$ & $i=2, \beta_{2}=1^{*}$ \\
\hline Period taken for calculations, $T_{c i}$ & April 25 May 8, 2021 & April 25 May 8, 2021 & December 11-24, 2020 \\
\hline$I_{i}$ & $15,895.4703455678$ & $2,993.09405674162$ & 581.6852057918 \\
\hline$R_{i}$ & $1,057,266.11194015$ & $199,185.048800401$ & $140,084.171937066$ \\
\hline$N_{i}$ & $3,102,717.088$ & 571,480 & 343,800 \\
\hline$v_{i}$ & $2,137,169.15821761$ & $388,684.616416235$ & $203,678.101450066$ \\
\hline$\alpha_{i}$ & $1.18748428868345 \mathrm{e}-07$ & $6.52942943554382 \mathrm{e}-07$ & $1.26938469796243 \mathrm{e}-06$ \\
\hline$\rho_{i}$ & 0.253785479764225 & 0.253788877557122 & 0.258545865290753 \\
\hline $1 / \rho_{i}$ & 3.94033575494167 & 3.94028300068005 & 3.86778569781199 \\
\hline$r_{i}$ & 0.999979810302661 & 0.99997979869081 & 0.999943364258809 \\
\hline$S_{i \infty}$ & $1,866,781$ & 338,877 & 188,661 \\
\hline$V_{i \infty}$ & $1,235,936$ & 232,603 & 155,139 \\
\hline Final day of the epidemic wave & March 14, 2022 & January 18, 2022 & January 16, 2022 \\
\hline
\end{tabular}

*Nesteruk and Benlagha (2021).

Source: The author.

Figure 1 - Visible second (black) and third (red) pandemic waves in Qatar. SIR simulations (lines) calculated at $\beta_{i}=1$.

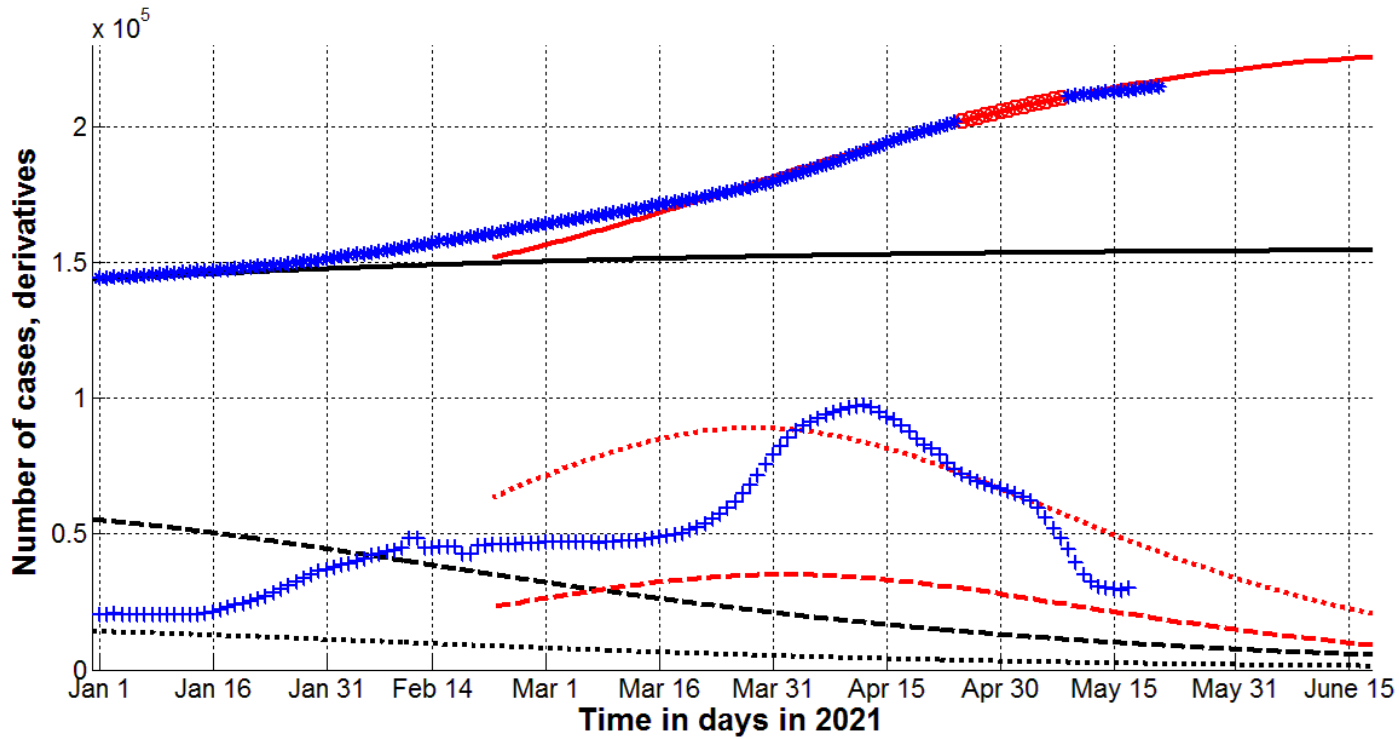

Visible second (black), calculated in Nesteruk and Benlagha (2021), and third (red) pandemic waves in Qatar. SIR simulations, "lines", calculated at $\beta_{i}=1$, i=2,3. Numbers of victims $V(t)=I(t)+R(t)$ "solid lines". "Dashed lines" show the numbers of infectious persons $I(t)$ multiplied by 10 . "Dotted lines" represent the derivatives $d V / d t$, equation (6), multiplied by 100 . Markers show accumulated numbers of laboratory-confirmed cases $V_{j}$, and derivatives. Red "circles" correspond to the accumulated numbers of cases taken for calculations of the third wave, during period of time $T_{c 3}$. Blue "stars" show the number of cases beyond $T_{c 3}$. "Crosses" represent the first derivatives, equation (8), multiplied by 100.

Source: The authors.

The results are shown in Table 2 , second column. It can be seen that the correlation coefficient $r_{3}$ for the invisible wave 3 is higher than for its visible part, compare values in the second and third columns. There is a huge difference in the optimal values of parameters $N_{i}, v_{i}, \alpha_{i}$ and the final sizes $V_{i \infty}$; large difference in the epidemic duration, but the estimations of average time of spreading the infection $1 / \rho_{i} \approx 3.9$ days are very close, compare second and third column in Table 2.
Red "lines" in Figure 2 represent the SIR curves for the invisible dynamics of the third epidemic wave in Qatar. "Solid line" shows the number of victims $V(t)=$ $R(t)+I(t)$, "dashed line" the number of infectious persons $I(t)$ multiplied by 10 and dotted line - the derivative (6) multiplied by 100 . The accumulated numbers the laboratory-confirmed cases $V_{j}$ (shown by blue stars and red circles) are much smaller than the theoretical estimation of real number of cases $V(t)=R(t)+I(t)$, shown by the red "solid line". 
Figure 2 - Real sizes of the third pandemic wave in Qatar for the calculated optimal value of the visibility coefficient $\beta_{3}=5.308$.

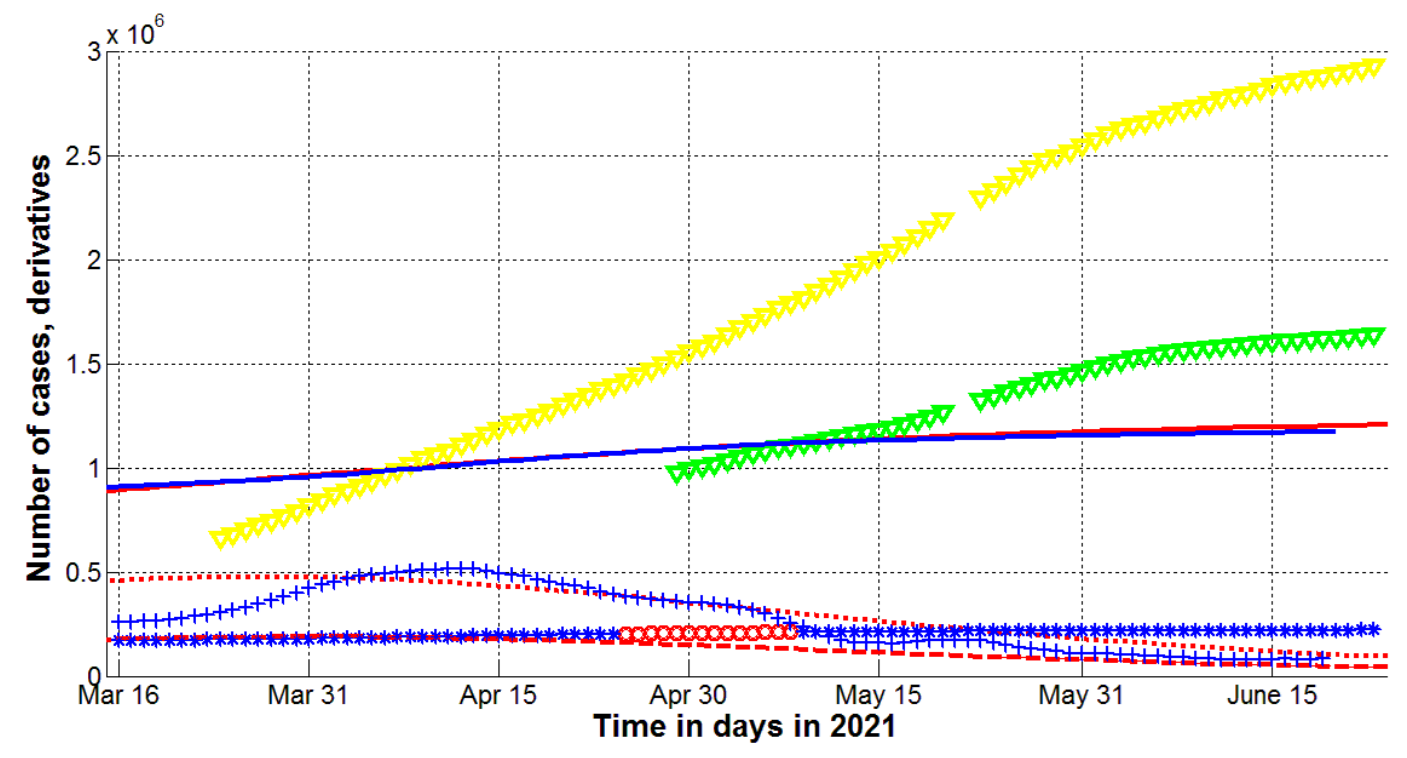

SIR simulations (red lines), numbers of vaccinations (yellow) and vaccinated persons (green). The solid red line shows the numbers of victims $V(t)=I(t)+R(t)$. The red "dashed line" represents the numbers of infectious persons $I(t)$ multiplied by 10 . The "dotted line" shows derivatives $d V / d t$, equation (6) multiplied by 100 . Markers show accumulated numbers of laboratory-confirmed cases $V_{j}$, from Table 1 , and derivatives. Red "circles" correspond to the accumulated numbers of cases taken for calculations of the third wave, during period of time $T_{c 3}$. Blue "stars" show the number of cases beyond $T_{c 3}$. "Crosses" show the first derivatives, equation (8), multiplied by $100 \beta_{3}$. The blue line represents smoothed accumulated number of laboratory-confirmed cases, equation (8) multiplied by $\beta_{3}$.

Source: The authors.

To check the reliability of the method and the results of calculations the accumulated number of laboratoryconfirmed cases $V_{j}$, listed in Table 1, was smoothed with use of equation (7) and corresponding values $\beta_{3} \bar{V}_{i}$ are shown by the blue "line" in Figure 2. It can be seen that theoretical estimation, the red "line", is very close the recorded number of cases multiplied by the optimal value of the visibility coefficient $\beta_{3}=5.308$. The values of the derivative of the smoothed accumulated number of laboratory-confirmed cases, calculated with the use of equations (7) and (8), have been multiplied by the optimal value of the visibility coefficient $\beta_{3}=5.308$ and shown in Figure 2 by blue "crosses" which are close to the theoretical "dotted line" after March 2021.

\section{Discussion}

The mass vaccination started in Qatar in late December 2020. The corresponding numbers of vaccinated people $P_{j}$ and vaccinations $Q_{j}$ are shown in Figure 2 by green and yellow markers, respectively. Despite the relatively rapid rate of vaccination, in June 2021, the number of fully vaccinated people $Q_{j}-P_{j}$ approached half of the population, Qatar experienced the new wave of pandemics with a sharp increase in the number of patients in MarchApril 2021, see blue "crosses" in Figure 1.
According to the forecast of the previous second wave made in Nesteruk and Benlagha (2021) using data before vaccination, the number of cases should stabilize rapidly in 2021, see the black "solid line" in Figure 1. We will probably see the effect of vaccination only after June 2021.

The calculated coefficient of epidemic visibility $\beta_{3}=5.308$ for Qatar correlates with the values $\beta_{9}=4.1024$ and $\beta_{10}=3.7$ obtained in Nesteruk (2021a, $2021 b$ ) for the ninth and tenth epidemic waves in Ukraine and the results of random testing in two kindergartens and two schools in the Ukrainian city of Chmelnytskii (NOVAK, 2021) which revealed the value 3.9.

The total testing in Slovakia, $65.5 \%$ of population was tested on October 31- November 1, 2020, revealed a number of previously undetected cases, equal to about $1 \%$ of the population (KOTTASOVÁ; ETZLER, 2020). On November 7 next $24 \%$ of the population was tested and found $0.63 \%$ of those infected (SLOVAKIA'S, 2020). According to the WHO report at the end of October, the number of detected cases in Slovakia was also approximately $1 \%$ of population (WHO, 2019).

Ignoring information about the large number of unreported cases can lead to incorrect recommendations for quarantine restrictions and overly optimistic forecasts of the COVID-19 pandemic duration. 
For example, the information about the real dependence $I(t)$ is important to estimate the probability of meeting an infected person with the use of simple formula, (NESTERUK, 2021a, 2021d):

$$
p(t)=\frac{I(t)}{N_{p o p}} .
$$

where $N_{\text {pop }}$ is the volume of population.

As of the end of June, 2021 the theoretical estimation yields the value $I \approx 5,000$, see the "dashed line" in Figure 2. Then the probability $p$ can be estimated as 0.0017 for Qatar. If only officially registered cases are taken into account, the corresponding probability will be approximately 5.3 times lower.

If current trends continue, new cases in Qatar will cease to be registered in January 2022, see the third column in Table 2. But the invisible cases will continue for another two months, see the second column in Table 2. During this long period, new strains of the coronavirus may emerge and cause a new epidemic wave, which will be unexpected, as the visible part of the epidemic seemed to have been overcome.

\section{Conclusions}

The application of generalized SIR model to the new COVID-19 pandemic wave in Qatar demonstrated once more its effectiveness in predictions of epidemic dynamics and estimations of the vaccination efficiency. The parameter identification procedure allowed calculating the coefficients of data incompleteness, approximately 5.3 in the end of April 2021. New simulations with the use of fresher datasets are necessary to update the estimation of the vaccination efficiency in Qatar. Probably, real sizes of the pandemic in other countries are also much large than the number of registered cases. Thus, reassessments of the COVID-19 pandemic dynamics are necessary, to avoid new unexpected waves.

\section{Acknowledgments}

The author is grateful to Oleksii Rodionov for his help in collecting and processing data.

\section{References}

FAHMAYA, A. E.; EL-DESOUKYA, M. M.; MOHAMED, A. S. A. Epidemic analysis of COVID-19 in Egypt, Qatar and Saudi Arabia using the generalized seir model. MedRxiv, New Haven, p. 1-19, 2020. DOI: https://doi.org/10.1101/2020.08.19.20178129.
GHANAM, R.; BOONE, E.; ABDEL-SALAM, A.-S. G. Seird model for Qatar Covid-19 outbreak: a case study. Letters in Biomathematics, Illinois, p. 1-10, 2020. Preprint. Available from: <https://arxiv.org/pdf/2005.12777.pdf > . Access in: June, 242021.

KERMACK, W. O.; MCKENDRICK, A. G. A Contribution to the mathematical theory of epidemics. Proceedings of the royal society of London, series A., London, v. 115, p. 700-721, 1927.

KOTTASOVÁ, I.; ETZLER, T. Slovakia tested most of the country in two days. Here's how they did it and what they found. $C N N$, Atlanta, 2020. Available from: <https://edition.cnn.com/2020/11/02/europe/sl ovakia-mass-coronavirus-test-intl/index.html $>$. Access in:2 nov. 2020.

LANGEMANN, D.; NESTERUK, I.; PRESTIN, J. Comparison of mathematical models for the dynamics of the Chernivtsi children disease. Mathematics in computers and simulation, [London], v. 123, p. 68-79, 2016. DOI: 10.1016/j.matcom.2016.01.003. Access in: June, 242021.

MURRAY J. D. Mathematical biology I/II. New York: Springer, 2002.

NESTERUK, I. Visible and real sizes of new COVID-19 pandemic waves in Ukraine. Innov Biosyst Bioeng, Kyiv, v. 5, n. 2, p. 85-96, 2021 a. DOI: $10.20535 /$ ibb.2021.5.2.230487.

NESTERUK, I. COVID19 pandemic dynamics. Singapore: Springer Nature, 2021b. DOI 10.1007/978-981-33-64165.

NESTERUK, I. Procedures of parameter identification for the waves of epidemics. In: NESTERUK, I. COVID-19 Pandemic Dynamics. Singapore: Springer Nature, 2021c. p. 133-139. DOI 10.1007/978-981-33-6416-5_10.

NESTERUK, I. Classical SIR model and the exact solution of differential equations. In: NESTERUK, I. COVID19 Pandemic Dynamics. Singapore: Springer Nature, 2021d. p. 23-32. DOI: 10.1007/978-981-33-6416-5_4.

NESTERUK, I.; BENLAGHA, N. Predictions of Covid19 pandemic dynamics in Ukraine and Qatar based on generalized sir model. Innov Biosyst Bioeng, Kyiv, v. 5, n. 1, p. 37-46, 2021. DOI: 10.20535/ibb.2021.5.1.228605. 
NOVAK, T. An experiment with mass testing for COVID19 was conducted in Khmelnytsky (in Ukrainian). Podillya NEWS, Kiev, 2021. Available from: <https://podillyane ws.com/2020/12/17/u-shkolah-hmelnytskogo-provely-e ksperyment-z-testuvannyam-na-covid-19/>. Access in: June, 242021.

OUR WORLD IN DATA. COVID-19 Dataset by Our World in Data, 2021. Available from: <https://github.com /owid/covid-19-data/tree/master/public/data $>$. Access in: June, 242021.

SLOVAKIA'S second round of coronavirus tests draws large crowds. Voa, Lang, 2020. Available from: <https: //www.voanews.com/covid-19-pandemic/slovakias-se cond-round-coronavirus-tests-draws-large-crowds $>$. Access in: 7 nov. 2020.

WEINBERGER, D. M., COHEN, T., CRAWFORD, F. W., MOSTASHARI, F., OLSON, D., PITZER, V. E., REICH, N., G., RUSSI, M., SIMONSEN, L., WATKINS, A., VIBOUD, C. Estimating the early death toll of COVID-19 in the United States. MedRxiv, New Haven, p. 1-28, 2020. Preprint. DOI: https://doi.org/10.1101/2020.04.15.20066431.

\section{WHO - WORLD HEALTH ORGANIZATION} Coronavirus disease (COVID-19) weekly epidemiological update and weekly operational update. Geneva: WHO, 2019. Available from: <https://www.who.int/emergencie s/diseases/novel-coronavirus-2019/situation-reports/>. Access in: June, 242021.

ZHEN, L. Coronavirus: 'strange pneumonia' seen in Lombardy in November, leading Italian doctor says. South China Morning Post, Hong Kong, 22 mar. 2020. Available from: <https://www.scmp.com/news/china/society/articl e/3076334/coronavirus-strange-pneumonia-seen-lomba rdy-november-leading >. Access in: June, 242021. 